\title{
A comparison of the acute-phase response in middle aged and elderly patients
}

\author{
Jean Woo $^{1}$, M. Arumanayagam ${ }^{2}$, D. MacDonald ${ }^{2}$ and K.S. Woo ${ }^{1}$ \\ Departments of ${ }^{1}$ Medicine and ${ }^{2}$ Chemical Pathology, The Chinese University of Hong Kong, Prince of Wales \\ Hospital, Shatin, NT, Hong Kong.
}

\begin{abstract}
Summary: The acute phase response in middle aged and elderly patients was compared by measuring the ratio of the peak $\mathrm{C}$-reactive protein to peak creatine kinase level during the three day period after acute myocardial infarction. No difference in ratio was observed between a middle aged group of 14 patients (10.2 \pm 4.0 mean \pm s.e.), and an elderly group of 13 patients $(9.1 \pm 1.5)$. C-reactive protein levels in two groups of middle aged and elderly control patients were similar $(10.1 \pm 0.04 \mathrm{mg} / \mathrm{l}$ and $11.8 \pm 0.10 \mathrm{mg} / \mathrm{l}$ respectively). Production of $\mathrm{C}$-reactive protein does not appear to be impaired in the elderly.
\end{abstract}

\section{Introduction}

It is well known that host defences against infection in the elderly are impaired. Many parameters of the host defence system have been investigated. ${ }^{1}$ However, little is known of the magnitude of the acute-phase response in old age compared with that in younger subjects, although it has been demonstrated that elderly patients do mount an acute phase response with increased serum C-reactive protein (CRP) values in infections. ${ }^{2}$ It is difficult to compare the magnitude of the acute phase response in elderly and in younger patients to a given stimulus, since the magnitude of the stimulus (or extent of inflammation) is difficult to quantify. It has been observed that after myocardial infarction, CRP rises to a maximum after 72 hours and the peak level is proportional to the extent of tissue injury as judged by the level of cardiac enzymes. ${ }^{3}$ Therefore myocardial infarction may provide a model where the size of the stimulus may be assessed semi-quantitatively by measuring the peak creatine kinase (CK) enzyme levels reached. ${ }^{4,5}$ The ratio of peak CRP level to peak CK level would then be an indication of the magnitude of the acute phase response and may be used for comparison in the two age groups.

\section{Method}

Subjects aged 60 years or less and 70 years or over admitted consecutively into the coronary care unit of a general hospital over a 12 month period were studied. The diagnosis of myocardial infarct was based on

Correspondence: Jean Woo, M.A., M.A., M.B., B.Chir (Cantab), M.R.C.P. (UK).

Accepted: 30 August 1988 electrocardiographic changes together with elevation of creatine kinase (CK), aspartate transaminase (AST) and lactate dehydrogenase (LDH) over a 3 day period from the time of admission. The WHO criteria for electrocardiographic diagnosis of myocardial infarction were used. ${ }^{6} \mathrm{CK}, \mathrm{AST}$ and $\mathrm{LDH}$ values greater than 218,64 , and $213 \mathrm{IU} / 1$ respectively were considered abnormal. Ten $\mathrm{ml}$ of venous blood collected from an antecubital vein daily for the first three days were divided into two aliquots. Five $\mathrm{ml}$ were placed in a plain tube, the serum separated by centrifugation, and transferred to biofreeze tubes for storage at $-70^{\circ} \mathrm{C}$, for analysis of CRP. CRP level was determined by EMIT $^{\mathrm{R}}$ (Syva Co, Palo Alto, CA, USA) adapted to a Cobas-Bio centrifugal analyser (Roche Diagnostica, Basle, Switzerland). The remaining $5 \mathrm{ml}$ were placed in a heparinized container for cardiac enzyme measurement within two hours of collection of the sample. Total CK was determined on an Encore centrifugal analyser (Baker Instruments Corp., Allentown, PA, USA) using reagent kits obtained from the same company.

Since CRP level will be raised in many other inflammatory conditions, subjects found to have any infections, liver and renal diseases, neoplasia, and chronic inflammatory diseases such as systemic lupus erythematosus or the arthritides were excluded from the study. Patients with subendocardial infarcts were also excluded as CRP levels do not rise unless the infarct is transmural. ${ }^{8}$

CRP levels in subjects in these two age groups without the above diseases attending outpatient clinics

(C) The Fellowship of Postgraduate Medicine, 1989 
were also determined from venous samples taken on one occasion. The diagnoses in these subjects include neuroses, vague somatic complaints for which no underlying diseases could be found (e.g. dizziness, epigastric distension, headache), hypertension and diabetes mellitus. In none of these subjects was blood taken solely for CRP estimation for this study.

The peak CRP to peak CK ratio was calculated for each subject with myocardial infarct. As this value was very small, the ratio was expressed as $\mathrm{CRP} / \mathrm{CK} \times 10^{2}$. Wilcoxon's Rank Sum test was used to detect any significant difference in the ratio between subjects in the two age groups. The CRP levels in the two control groups were also analysed for any significant difference in the same way.

\section{Results}

Fourteen middle aged patients (mean age $53.4 \pm 7.2$ years) and 13 elderly patients ( $76.2 \pm 5.7$ years) with myocardial infarction were studied. All but one of the younger patients presented with chest pain, while 6/13 of the older patients presented with shortness of breath only. The peak CK and CRP values reached were not related to the mode of presentation or the outcome. The peak CRP to peak CK ratio $\times 10^{2}$ of the middle aged and elderly patients were (mean \pm s.e.) $10.23 \pm 4.0$ and $9.12 \pm 1.5$ respectively [mean difference $(95 \% \mathrm{CI})$ $1.11(-4.9$ to 7.1$)$ ]. The mean ages ( \pm s.d.) of the non-infarction control groups were $53.1 \pm 6.1$ and $74.1 \pm 4.1$ years and the mean CRP ( \pm s.e.) $10.1 \pm 0.04$ and $11.8 \pm 0.10 \mathrm{mg} / 1$ respectively [mean difference $(95 \% \mathrm{CI}) 1.7$ (1.6 to 1.8$)]$. This difference was not statistically significant. There was no significant difference in ratio between the two age groups, between those with different modes of presentation, or between survivors and those who died.

\section{Discussion}

The acute phase response is a non-specific response by the host to inflammation, which would result in the removal of the precipitating agent, the removal of damaged tissue, and repair of the affected tissue. C-reactive protein (CRP), a major product of the acute-phase response, has been studied extensively ${ }^{9}$ and in certain situations such as myocardial infarction, bears a quantitative relationship to the extent of damage. ${ }^{10,11}$

The synthesis of CRP by hepatocytes is thought to be induced by interleukin 1 , a factor secreted by activated macrophages. ${ }^{12,13}$ Other macrophage products may also induce CRP synthesis. There have been suggestions that the production and responsiveness of interleukin 1 and 2 are altered during ageing. ${ }^{14,15}$ As interleukin 1 stimulates CRP production, any deficiency may be reflected in a reduced level of CRP in response to inflammation.

Reduced levels of CRP may give rise to impaired response to inflammation, since bound CRP has been shown in animal studies to activate complement, ${ }^{16}$ is required for phagocytosis by macrophages and lymphocytes, ${ }^{17}$ and modulates release of inflammatory mediators by platelets at the sites of inflammation. Although the function of human CRP is not known, impaired defence mechanisms against infection in the elderly may be partly due to impaired acute phase response, as measured by reduced production of CRP.

The results show that the CRP response to a given stimulus in middle aged and elderly subjects is the same. Various assumptions are made in arriving at this conclusion. Firstly, the kinetics of CK and CRP after myocardial infarction are assumed to be the same in both age groups. Peak CK values should be achieved within 24 hours of the time of infarction, and since most patients were admitted within this period, it is unlikely that we would have missed the peak. However, since the kinetics of CRP following myocardial infarction in the elderly is unknown, we have assumed that the peak should be reached by 72 hours. ${ }^{3,11}$ In most of the subjects, the CRP value was highest in the third specimen. However, even if the peak CRP value should be delayed in the elderly group, the CRP/CK ratio (and thus magnitude of the acute phase response) would be higher and not lower.

Secondly, the quantitation of the magnitude of the stimulus, i.e. size of infarct, is not absolute. More accurate methods of determining infarct size such as thallium scanning or cumulative CK measurements were not used. Nevertheless, the latter has been shown to correlate well with the peak of the daily serum enzyme estimations despite the wide sampling error. ${ }^{5}$

It is possible that the number of subjects studied was too small, or that the age difference between the two groups of subjects is not great enough to demonstrate any difference. In practice it would be very difficult to recruit an even younger age group of patients with myocardial infarction.

Taking into account the limitations of this study, we can conclude tentatively that the impaired defence mechanism observed with ageing ${ }^{18}$ is unlikely to be due to a decreased production of CRP. 


\section{References}

1. Finkelstein, M.S. Defences against infection in the elderly: the compromises of ageing. Triangle 1984, 23: 57-64.

2. Kenny, R.A., Hodkinson, H.M., Cox, M.L., Caspi, D. \& Pepys, M.B. Acute phase protein response to infection in elderly patients. Age Ageing 1984, 13: 89-94.

3. Kushner, I., Broder, M.L. \& Karp, D. Control of the acute phase response. Serum C-reactive protein kinetics after acute myocardial infarction. J Clin Invest 1978, 61: 235-242.

4. Sobel, B.E. \& Shell, W.E. Serum enzyme determinations in the diagnosis and assessment of myocardial infarction. Circulation 1972, 45: 471-482.

5. Thompson, P.L. \& Robinson, J.S. Stroke after acute myocardial infarction: relation to infarct size. $\mathrm{Br} \mathrm{Med} \mathrm{J}$ 1978, 2: 457-459.

6. International collaborative trial on the primary prevention of ischaemic heart disease. A manual of methods and procedures. Ed. E.A.J. Scott. WHO Offset Document CVD/75.4 WHO, Geneva, 1975.

7. Szasz, G., Gruber, W. \& Berut, E. Creatine kinase in serum: 1. Determination of optimum reaction condition. Clin Chem 1976; 22: 650-656.

8. Pietila, K., Harmoinen, A., Poyhonen, L. \& Ruosteenoja, R. C-reactive protein in subendocardial and transmural myocardial infarcts. Clin Chem 1986, 32: 1596- 1597 .

9. Pepys, M.B. \& Baltz, M.L. Acute phase proteins with special reference to $\mathrm{C}$-reactive protein and related proteins (Pentaxins) and serum amyloid $\mathrm{A}$ protein. $A d v$ Immunol 1983, 34: 141-211.
10. Kushner, I., Gervurz, H. \& Benson, M.D. C-reactive protein and the acute-phase response. $J$ Lab Clin Med 1981, 97: 739-749.

11. De Beer, F.C., Hind, C.R., Fox, K.M., Allan, R.M., Maseri, A. \& Pepys, M.B. Measurement of serum C-reactive protein concentration in myocardial ischaemia and infarction. Br Heart $J$ 1982, 47: 239-243.

12. Dinarello, C.A. Interleukin 1 and the pathogenesis of the acute-phase response. $N$ Engl $J$ Med 1984, 311: 1413-1418.

13. Dinarello, C.A. \& Mier, J.W. Current concepts - lymphokines. N Engl J Med 1987, 317: 940-945.

14. Chang, M.P., Makinodan, T., Peterson, W.J. \& Strehler, B.L. Role of $\mathrm{T}$ cells and adherent cells in age-related decline in murine interleukin 2 production. $J$ Immunol 1982, 129: 2426-2430.

15. Rosenberg, J.S., Gilman, S.C. \& Feldman, J.D. Effects of aging on cell cooperation and lymphocyte responsiveness to cytokines. J Immunol 1983, 130: 1754-1758.

16. Seigel, J., Osmand, A.P., Wilson, M.F. \& Gervurz, H. Interaction of C-reactive protein with the complement system. II. CRP-mediated consumption of complement by poly-L-lysine polymers and other polycations. $J$ Exp Med 1975, 142: 709-721.

17. Mortensen, R.F. \& Duskiewicz, H.A. Mediation of the CRP-dependent phagocytosis through mouse macrophage FC receptors. J Immunol 1977, 119: 1611 - 1616.

18. Bach, J.F. Immunosenescence. Triangle 1986, 25: 25-31. 